\title{
75 Aniversario de la Sociedad Española de Cardiología, Sevilla, España 2019
}

\author{
75 ${ }^{\text {th }}$ Anniversary of the Spanish Society of Cardiology, Seville, Spain 2019
}

\author{
Pedro Iturralde-Torres* \\ Sociedad Mexicana de Cardiología. Ciudad de México, México.
}

Distinguidos miembros de la mesa de honor, altas autoridades de la Sociedad Española de Cardiología y de la Sociedad Interamericana de Cardiología, invitados especiales,

Es un altísimo honor el que se me ha conferido de dirigir unas palabras en esta ceremonia de conmemoración del septuagésimo quinto aniversario de la Sociedad Española de Cardiología, en convergencia con la celebración del 75 aniversario de la fundación del Instituto Nacional de Cardiología Ignacio Chávez de México y de la Sociedad Interamericana de Cardiología.

He sido designado por el Dr. Marco Antonio Martínez Ríos en representación del Instituto Nacional de Cardiología Ignacio Chávez y su actual director general, el Dr. Jorge Gaspar, para expresar nuestra más alta consideración, sentimientos respetuosos y felicitaciones a la Sociedad Española de Cardiología y a la Sociedad Interamericana de Cardiología en esta conmemoración.

El Instituto Nacional de Cardiología Ignacio Chávez, primero en su género a nivel mundial, paradigma y modelo de emulación de numerosos institutos de otras naciones, fue fundado el 18 de abril de 1944 en México por el Maestro Ignacio Chávez, figura emblemática de la medicina, educación, cultura y humanismo en el siglo XX.

El Instituto Nacional de Cardiología es un instituto de excelencia médica y de justicia social; un hospital de alta especialidad con reconocidos expertos en el campo de ayuda humanitaria para los enfermos del corazón y de asistencia para los pacientes de bajos recursos económicos, subvencionados para la atención cardiológica de tercer nivel, que pugna por la prevención de las cardiopatías y ayuda a la rehabilitación de los enfermos cardiovasculares. El Instituto ha creado ciencia propia en investigación básica y clínica y se ha destacado por la creación de la Escuela Mexicana de Cardiología y por sus aportaciones revolucionarias al conocimiento, además de la formación de especialistas extranjeros de 47 naciones que, al reintegrarse a su medio, han sido el motor de grandes trasformaciones sociales, destacando en sus países como creadores de la ciencia, dirigentes de la acción académica, docente y asistencial en el campo de la Cardiología, la investigación y la salud pública.

En esta conmemoración es importante rememorar los profundos lazos de unión y poderosos vínculos entre la cardiología mexicana y la española. Un hecho único en la historia de la solidaridad humana fue la llegada del grupo de exiliados españoles, científicos, médicos, filósofos, matemáticos, profesores, poetas, artistas, que la diáspora de la migración y el exilio llevó hasta México. Del discurso pronunciado por el Maestro Chávez al ser investido como Doctor Honoris causa por la Universidad de Salamanca, me permito citar: «Fue así como México

\section{Correspondencia:}

*Pedro Iturralde-Torres

Juan Badiano, 1

Col. Sección XVI, Del. Tlalpan

C.P. 14080 , Ciudad de México, México

E-mail: smcardiologia @ prodigy.net.mx

1405-9940 @ 2019 Instituto Nacional de Cardiología Ignacio Chávez. Publicado por Permanyer México SA de CV. Este es un artículo Open Access bajo la licencia CC BY-NC-ND (http://creativecommons.org/licenses/by-nc-nd/4.0/).
Disponible en internet: 02-10-2019 Arch Cardiol Mex. 2019;89(3):209-210 www.archivoscardiologia.com 
recibió el beneficio de un haz de inteligencias superiores que España perdía y que México recogía amorosamente ofreciéndoles un hogar, abriendo para ellos las fronteras, sus pasaportes, leyes que les permitieran trabajar, abriendo el aula de la universidad y las puertas de los hogares como viejos amigos".

El Instituto Nacional de Cardiología y su fundador incorporaron a la vida académica a un grupo numeroso de sabios y profesores españoles, quienes derramaron su saber en las aulas y en las cátedras, y de investigadores que contribuyeron a revitalizar los laboratorios. Rendimos homenaje reverente a dos grandes figuras de exilio español en México, los investigadores Don Isaac Costero y Don Rafael Méndez, quienes fueron pilares de nuestra institución.

El Instituto Nacional de Cardiología, como institución educativa, abrió también sus puertas a América Latina, la anglosajona y Europa. De España acudieron 138 médicos al Instituto Nacional de Cardiología de México a obtener la preparación clínica y de investigación, y a su regreso se diseminaron por todas las regiones de España, en las que tuvieron un papel destacado y ocuparon puestos en hospitales y dirigieron Servicios de Cardiología en Barcelona, Bilbao, Madrid, Málaga, Oviedo, Pamplona, Santander, Santiago, Salamanca y Zaragoza, donde cimentaron las bases de la cardiología moderna española, orgullo nacional.

Ha sido en España, a finales del siglo pasado y en los albores del siglo xxi, donde más de un centenar de cardiólogos mexicanos nos hemos formado en alta especialidad, primordialmente en Madrid y Barcelona.

El Instituto Nacional de Cardiología fue el primero en su género y el lugar de nacimiento de la Sociedad Interamericana de Cardiología. El primer y segundo congresos se realizaron en México por el Instituto y en 1946, los delegados extranjeros, ilustres profesores europeos, hicieron la propuesta de crear la Sociedad Internacional de Cardiología. Fue así como el Instituto Nacional de Cardiología y la Sociedad Interamericana de Cardiología sellaron el vínculo entre los cardiólogos del mundo.

En estos largos y productivos 75 años, la Sociedad Interamericana de Cardiología ha agrupado a sociedades nacionales de cardiología en América y ha celebrado exitosamente congresos interamericanos que han permitido a los cardiólogos del Norte, Centro y Sudamérica y el Caribe compartir sus logros científicos en el combate a los trastornos cardiovasculares con sus vecinos y hermanos, y a la vez ampliar y estrechar los lazos entre los hombres de América.

La Sociedad Mexicana de Cardiología, a la que tengo el honor de presidir, ha expresado en múltiples ocasiones la admiración y el afecto a ambas Sociedades de Cardiología, por la mutua colaboración durante décadas.

Así hemos llegado a la hora presente, en que se vuelven a encontrar España y México en el crucero de la historia. El lazo del pasado se estrecha con el vínculo nuevo, hoy frente al reto de nuestro tiempo, en la marcha hacia el futuro, la Sociedad Española de Cardiología, la Sociedad Interamericana de Cardiología y el Instituto Nacional de Cardiología Ignacio Chávez de México mantendrán apretados los lazos que unen a Hispanoamérica con España, lo que permitirá mantener viva la fe en la solidaridad humana.

Brindemos por una larga vida cumpliendo el dictum del lema que inspira la mística de nuestro Instituto: Amor y ciencia al servicio del corazón. 